\title{
Hepatic Hilar Lymph Node Resection in Cytoreductive Surgery for Advanced Ovarian Cancer: A Necessity or Not?
}

\author{
Honglian Huang ${ }^{l, *}$ \\ Renjie Wei ${ }^{1} *$ \\ Ying Long ${ }^{2}$ \\ Yu Mo' \\ Yu Xie $\mathbb{I D}^{3}$ \\ Desheng $\mathrm{Yao}^{2}$
}

'Hechi People's Hospital, Hechi City, Guangxi Zhuang Autonomous Region, People's Republic of China; ${ }^{2}$ Gynecologic Oncology Department, Guangxi Medical University Affiliated Cancer Hospital, Nanning City, Guangxi Zhuang

Autonomous Region, People's Republic of China; ${ }^{3}$ Obstetrics and Gynecology Hospital of Fudan University, Shanghai, People's Republic of China

*These authors contributed equally to this work
Correspondence: Desheng Yao; Yu Xie $\mathrm{Tel} / \mathrm{Fax}+86-77 \mathrm{I}-5330700$;

Tel $+86-21-33189900$

Fax +86-2I-63450900

Email yaodesheng@gxmu.edu.cn;

yuxiel8@fudan.edu.cn
Objective: This review aims to clarify the necessity of hepatic hilar lymph node resection on advanced ovarian cancer patients.

Background: PARP inhibitors and surgery have significantly improved the survival of patients with ovarian cancer. However, for patients with advanced ovarian cancer, there are often extensive epigastric disseminated metastatic lesions, especially the lymph nodes in the hepatic hilar area. Because of the complicated anatomical relationship and lack of experience in this area, this is easily ignored by gynecological oncologists.

Methods: Through the retrieval and analysis of the current database, namely PubMed, Medline, Web of Science, EMBASE, Cochrane Library, and Wangfang, etc., the literature regarding this topic published before March 2021 were thoroughly investigated.

Conclusion: For the hepatic hilar regional lymph node surgery, through careful preoperative evaluation, surgical-indication clarification, appropriate case selection, standardized surgical operations and multidisciplinary cooperation with general surgeons, the prognosis of patients is significantly improved. Postoperative complications are also safe and controllable and convincing. To conclude, the application of hilar region lymph node cytoreductive surgery for patients with advanced ovarian cancer is a feasible and preferred choice.

Keywords: advanced ovarian cancer, hilar lymph node, cytoreductive surgery

\section{Introduction}

In recent years, although the efficacy of poly adenosine diphosphate ribose polymerase inhibitor (PARPi) in the treatment of ovarian cancer has attracted worldwide attention, ${ }^{1}$ the majority of newly diagnosed epithelial ovarian cancer patients are treated with radical surgery. However, there is an alternative option of 3 or more cycles of neoadjuvant chemotherapy (NACT) prior to debulking surgery and adjuvant chemotherapy for selected patients, although still lacking evidence of the consensus about which subset of patients is the best candidates for this approach and how to best select them. Nevertheless, NACT offers the opportunity to test upfront chemosensitivity and to identify patients at higher risk of relapse. ${ }^{2}$

The classification of ovarian cancer is based on the origin and histopathology, while the surgical treatment also differs. Epithelial ovarian cancer (EOC) is the main form of the disease and mostly consists of the very heterogeneous, high grade serous ovarian cancer. On the other hand, the non-epithelial ovarian cancers (NEOC) account for about $10 \%$ of all ovarian cancers, which include germ cell tumors, sex cord-stromal cell origin, small-cell carcinomas and sarcomas. Due to 
high chemotherapy sensitivity and good prognosis of germ cell tumors, the recommended surgical staging is much less aggressive. Unilateral salpingo-oophorectomy with preservation of the contralateral ovary and the uterus is considered adequate surgical treatment for the majority of premenopausal patients with germ cell tumors. ${ }^{3}$

Accumulating data suggested that the thoroughness of surgical treatment directly affects the patient's prognosis. ${ }^{4}$ When performing tumor cytoreductive surgery, all tumorous lesion in the pelvis should be removed as much as possible, and occult lesions in the upper abdomen or retroperitoneum should be evaluated at the same time. ${ }^{4}$ Resection of the upper abdominal lesions, including the lymph nodes in the hepatic hilar area, can significantly improve the prognosis of patients with advanced ovarian cancer. ${ }^{5}$ However, the anatomical structure of the hilar area is complicated. The lymph nodes in this area are adjacent to important structures such as the biliary system, hepatic artery system, portal vein system, and inferior vena cava, which greatly increases the difficulty of the operation. Due to various scruples, the surgeon seldom explores this area during cytoreductive surgery, providing a "refuge" for residual tumors. ${ }^{6}$

In this review, we aim to answer two questions in this field, namely 1 . How to improve the safety and feasibility of surgical resection of hepatic hilar lymph nodes for advanced ovarian cancer patients; 2. Whether surgical resection of hepatic hilar lymph nodes brings survival benefits for these patients. This article focuses and elaborates on this topic together with related issues in detail. We also included a workflow diagram of this review process of the article for clarification (Figure 1).

\section{The Anatomical Structure of the Hepatic Hilar Area}

The hepatic portal area usually refers to the area where the hepatic artery, portal vein, and bile duct connecting the liver. Currently, this anatomical area also includes the hepatoduodenal ligament and hepatogastric ligament below porta hepatis. Hepatic hilar regional lymph nodes are located posterior to common hepatic artery, hepatic artery and portal vein, between portal vein and inferior vena cava. ${ }^{5,7}$ Hepatoduodenal ligament and hepatogastric ligament are part of the omentum, which is the double layer of peritoneum connecting the stomach and duodenum to the liver. The definition of this hepatic hilar area in ovarian cancer surgery is different from the hilar area defined in the Japanese "Biliary Duct Cancer Management Protocol". 8
The extent of lymph node resection in the hilar area usually depends on the definition of the hilar regional lymph node, that is, the location of the lymph node where tumors are most common and most likely to metastasize. This involved lymph node range is usually closely related to the path of lymphatic drainage under physiological conditions. ${ }^{9}$ In the vascular structure of the hepatic portal area, while the portal vein is relatively easy to identify, the hepatic artery system and biliary system often have many variations. This leads to the complicated spatial relationship between the three systems. ${ }^{8}$ If there is a space-occupying disease in the portal area, pushing or compressing the vasculature may displace the anatomical relationship, which will interfere the judgment of surgeon. Hence, it is very likely to accidentally damage the vascular structure of the hepatic portal area during the operation. ${ }^{9}$ Therefore, it is extremely important to fully evaluate the space-occupation of the hilar area and its anatomical relationship with the vascular structure before performing accurate hilar lymph node resection surgery. An intraoperative picture of the porta hepatic was displayed with annotated structures (Figure 2).

\section{Lymph Node Metastasis in the Hepatic Hilar Area}

The most common mode of dissemination of ovarian cancer cells is through the peritoneal route, followed by lymphatic system metastasis. Patients with lymph node metastasis tend to have a higher recurrence rate and a poor prognosis. There are few reports about lesions or lymph node metastasis in the hepatic hilar area after thorough literature review. Song et $\mathrm{al}^{10}$ reported 11 hepatic hilar lesions in patients with recurrent or advanced ovarian cancer. The average size of these lesions was $2.0 \mathrm{~cm}(0.7 \sim 4 \mathrm{~cm})$. All lesions were completely removed with the assistance of hepatobiliary surgeons achieving ideal tumor reduction. Postoperative pathology was confirmed as ovarian cancer metastatic lesions. Martinez et $\mathrm{al}^{11}$ found that 28 patients with advanced ovarian cancer had hepatic hilar area lesions with/without enlarged lymph nodes, and 15 cases were found to have lymph node metastasis after resection of the lesions. Raspagliesi et $\mathrm{al}^{6}$ reported that 25 cases of hilar metastasis were discovered in 37 patients with advanced ovarian cancer, with the hepatic portal metastasis rate as high as $67 \%$. This included 22 cases of hepatic hilar peritoneum and 5 cases of hepatic hilar lymph nodes ( 2 cases presented with peritoneum combined with lymph node metastasis). Tozzi et $\mathrm{al}^{7}$ performed tumor cytoreductive 


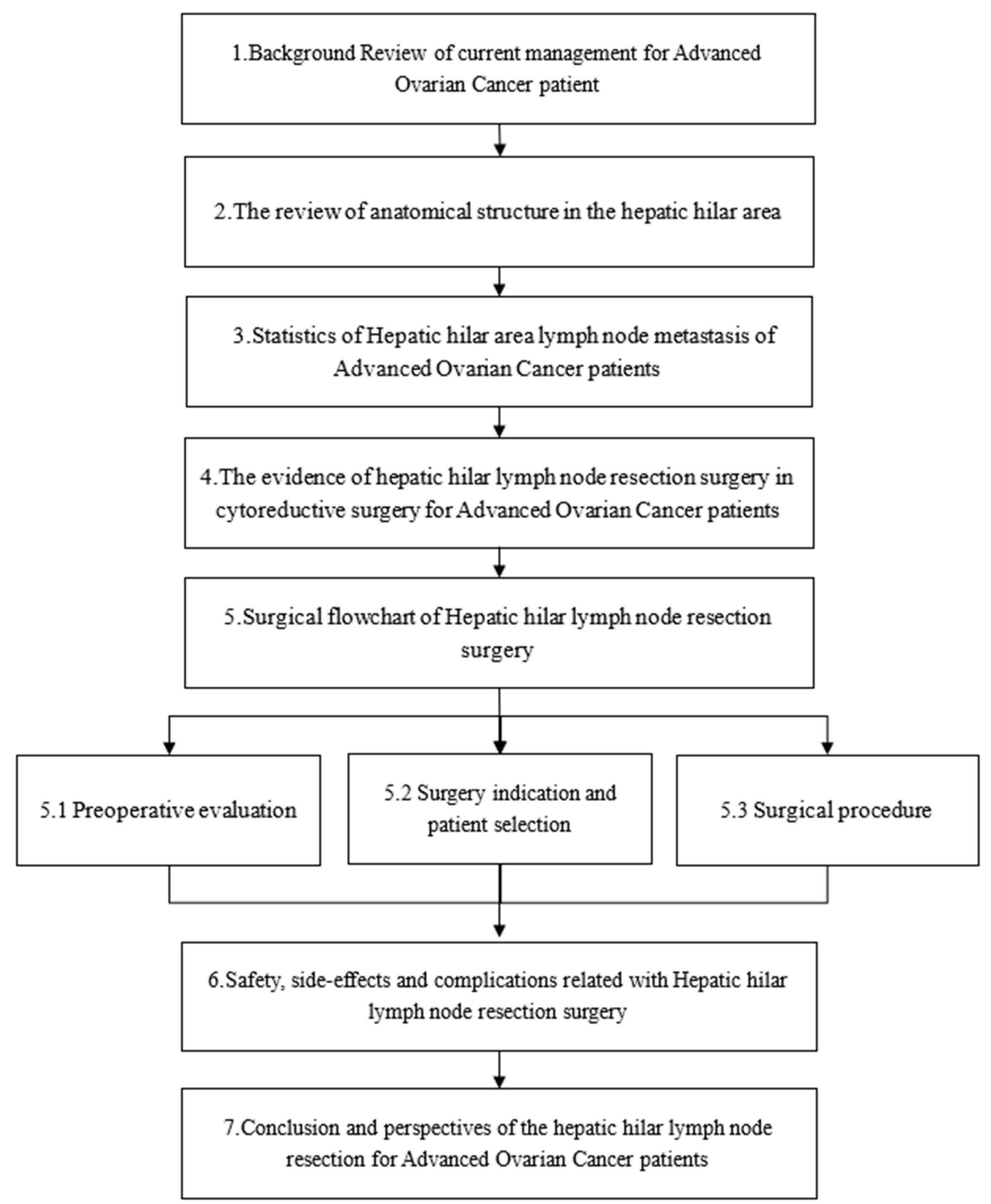

Figure I Workflow diagram of the article.

surgery on 216 patients with stage IIIC-IV ovarian cancer. During these operations, 31 cases were found to have visible lesions in the hepatic hilar area. Among which, the hepatic hilar area lesions could be completely resected in 28 cases, and 13 cases were found to have lymph node metastases in the hepatic portal area with lymph node diameter of 1.8 to $3.5 \mathrm{~cm}$. These lymph nodes are distributed around the portal vein, celiac trunk, superior mesenteric artery, hepatic artery, right gastric artery and left gastric artery, etc. The prognosis of patients with hepatic hilar lymph node metastasis is worse compared to those without, and the patient's progression-free survival (PFS) is only 16 months. ${ }^{12}$ Adequate preoperative imaging evaluation, careful exploration of the upper abdomen during the operation, and superb surgical skills of the surgeons are the guarantee for the safe and complete removal of the lymph nodes in the hepatic hilar area.

\section{The Evidence of Surgery in the Hepatic Hilar Area}

Advanced ovarian cancer often presents extensive epigastric dissemination and metastasis, such as tumors involving the diaphragm, liver, spleen, omentum, hepatic hilum, etc. Sometimes, the lesions are diffusely distributed on the surface of the intestine and peritoneum. In these cases, 


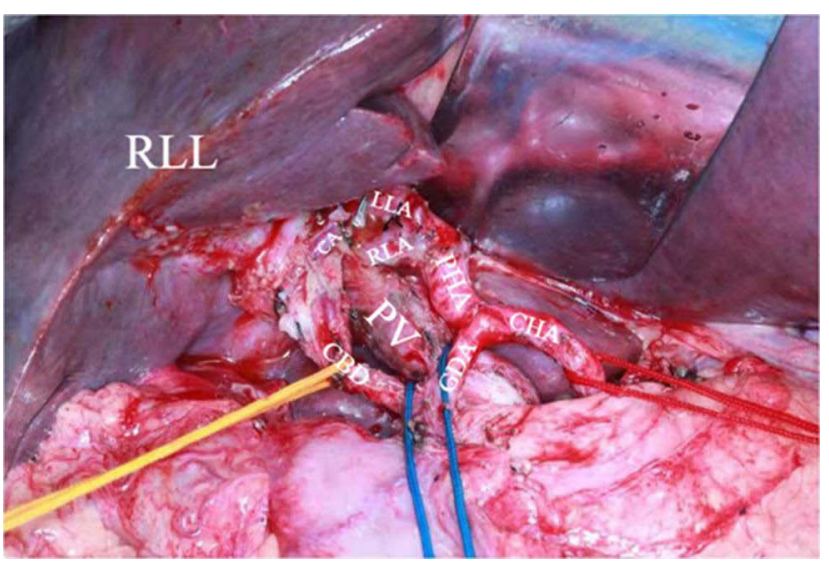

Figure 2 Anatomy of hepatic hilar region.

Abbreviations: RLL, right lobe of liver; CHA, common hepatic artery; GDA, gastroduodenal artery; PHA, proper hepatic artery; RLA, right liver artery; LLA, left liver artery; CA, cystic artery; PV, portal vein; CBD, common bile duct.

more extensive upper abdominal surgery is needed to achieve complete tumor resection or ideal tumor cell reduction. In 1975, Griffiths et $\mathrm{al}^{13}$ first reported that patients could benefit with improved overall survival (OS) and progression-free survival (PFS) if the maximum diameter of residual lesions after surgery was less than $1.5 \mathrm{~cm}$. For every $10.0 \%$ tumor bulk reduction, the median survival rate of patients will increase by $5.5 \%{ }^{14}$ It can be interpreted that the thoroughness of surgical treatment has a huge impact on the prognosis of patients, so that the National Comprehensive Cancer Network (NCCN) ${ }^{4}$ guidelines defined ideal cytoreductive surgery as the diameter of residual tumor lesions less than $1 \mathrm{~cm}$ after surgery, achieving the goal of no visible residue. In other words, for upper abdominal surgery including the hepatic hilar area, if the surgical techniques are mature, even the tumor involved adjacent organ tissues should be removed to achieve the desired tumor reduction. Aletti et $\mathrm{al}^{15}$ found that actively carrying out upper abdominal surgery and minimizing residual lesions can significantly benefit the survival of patients with extensive abdominal lesions. The complicated anatomy of the hepatic hilar area should not be an obstacle of ideal cytoreductive surgery. ${ }^{7}$ Some gynecologists even believe that hepatic hilar area surgery should become one of the basic surgical skills of gynecological oncologic surgeons. ${ }^{10}$

\section{Preoperative Evaluation, Case Selection and Surgical Procedure Preoperative Evaluation}

Preoperative imaging examination occupies an irreplaceable position in the operation of the hepatic hilar area. At present, clinical imaging examinations that can be used to assess the status of lymph node metastasis in the hepatic hilar area include: X-ray computed tomography (CT), Magnetic Resonance Imaging (MRI) and positron emission Tomography/X-ray computed tomography (Positron Emission Tomography/Computed Tomography, PET/CT). The accuracy of CT examination for the detection of positive retroperitoneal lymph nodes for ovarian cancer is as high as $94.01 \% .{ }^{16}$ However, it is biased to judge whether metastasis occurs only by the size and morphological characteristics of lymph nodes in imaging. The latest technology of CT examination based on image texture analysis is expected to improve retroperitoneal lymph nodes detection rate in clinical practice. ${ }^{17}$ The signs of metastatic lymph nodes on MRI may manifest as one or some characteristics as following: dirt-like changes in the abdominal cavity, linear or irregular linear thickening of the peritoneum, visible plaques, nodules or masses, and partial liquefaction necrosis. Studies have shown that the preoperative scoring system about the hepatic hilar area based on MRI can obtain results consistent with the laparoscopic scoring system. ${ }^{18}$ This scoring system may be used as a powerful clinical assistance which should be further evaluated and tested in larger clinical trial. PET/CT examination is a combined analysis of lymph node changes in molecular metabolism and standardized uptake values. Its diagnosis of lymph node metastasis is more objective, and the detection accuracy is higher than CT examination and MRI examination. ${ }^{19,20}$ However, PET/CT is an expensive test and its diagnostic accuracy of pelvic lymph node metastasis is better than that of other body part lymph node metastases. ${ }^{21}$ Even though $\mathrm{PET} / \mathrm{CT}$ examination is currently the best imaging method to assess lymph node metastasis, it still cannot replace surgical histopathological examination. Gynecologists should pay more attention to obtaining accurate preoperative diagnosis about whether the lymph nodes in the hepatic hilar area have metastasized and improving the preoperative imaging to determine the severity and range of suspected lymph nodes in the hepatic hilar area. 


\section{Case Selection}

There are few reports on the indications of hepatic hilar lymph node resection in the literature, but patients with the following factors should routinely consider hepatic hilar lymph node resection: ${ }^{7,11}$ (1) Preoperative imaging examination indicates lesions or enlarged lymph nodes in the hepatic hilar area; (2) Suspicious lymph node metastases in the hepatic hilar area detected during the operation; (3) If extensive upper abdominal metastases or more than 4 abdominal aortic lymph nodes metastases discovered, positive rate of hepatic hilar area lymph nodes will increase to $75 \%$, and routine surgical exploration is recommended.

\section{Surgical Procedure}

First, open the transverse colon and omentum during surgical exploration, lift up the stomach and omentum tissue, hepatic hilar area will be easily exposed together with the duodenum and pancreas. Second, use the vascular rubber band to pass through the lesser omental foramen and gently tract the hepatoduodenal ligament. The purpose is to expose surgical area and to achieve vascular control. In the third step, Kocher incision was used to free the descending segment of the duodenum to fully expose the porta hepatis, hepatic hilar lymph nodes and omental sac. Fourth step, evaluate the extent of tumor involvement in the hepatic hilar region with hilar and omental lymph nodes. After confirming that the hepatic hilar lymph nodes are resectable, the operation begins with peritoneal dissection. Open the peritoneum of the hepatoduodenal ligament in the tumor-free area to expose the hepatic artery and bile duct. Peritoneal dissection is usually performed between the lateral margin of the duodenum and the round ligament in the liver. In order to solve the peritoneal lesions behind the portal vein, the vascular rubber band was gently pulled inwardly, and the peritoneum was dissected from the dorsal side of the portal vein. Once the hepatic hilar structures are exposed, the enlarged hilar lymph nodes can be palpated, and the resection is carried out in a retrograde manner, that is, from the bifurcation of the proper hepatic artery to the gastroduodenal artery and the right gastric artery, along the common hepatic artery ascending to the splenic artery, left gastric artery and celiac artery, separating the area between the portal vein and the inferior vena cava. ${ }^{7,10}$ If it is found that the hepatic portal vessels are extensively invaded by the tumor during the operation and are relatively fixed, the surgical separation should be terminated and palliative treatment may be considered. The whole process was concluded in a workflow diagram (Figure 3 ). The current research is limited to patients with advanced ovarian cancer confirmed by preoperative imaging examination or swollen lymph nodes found in intraoperative exploration of the hepatic hilar area. ${ }^{10}$ It is not a systemic lymph node resection, and there is insufficient evidence to prove whether systemic lymph node resection in the hilar area is sufficient or beneficial to the survival of patients with advanced ovarian cancer. Therefore, it is generally believed that only the enlarged or suspicious lymph nodes in the hilar area need to be removed to achieve the desired tumor reduction. As for the hepatic hilar lymph node dissection, whether it is necessary to perform systematic and comprehensive hilar lymph node resection, it remains unknown.

\section{Safety and Side-Effects}

The core issue of the controversy related to the resection of the lymph nodes is whether the removal should be performed only to stage the disease or if the removal itself improves survival.

To further comprehend the issue, one must take into account that several studies have shown that systematic lymphadenectomy is associated with a risk of vascular injury, lymph cyst formation, pulmonary embolism and increased postoperative mortality even when performed by surgeons with extensive experience. ${ }^{22}$

The vasculature anatomy in the hepatic portal area is complicated. The hepatic artery, portal vein, and biliary tract are adjacent to each other, wrapped in the Glisson sheath, and there are many variations, ${ }^{8}$ which is undoubtedly a huge challenge for gynecological oncologists. Especially with tumor space-occupying compression, it is even more likely to cause structural displacement changes in the hepatic hilar area. Therefore, tumor reduction surgery in this area often requires the cooperation of hepatobiliary surgeons. Song et $\mathrm{al}^{10}$ reported that through interdisciplinary cooperation with hepatobiliary surgery, their team performed hilar regional lymph node resection on 11 cases of recurrent or advanced ovarian cancer. The operation process was smooth with no postoperative complications. Raspagliesi et $\mathrm{al}^{6}$ conducted a prospective study in which 25 patients with advanced ovarian cancer underwent hilar area lesion resection. Two patients had mild complications, one had hepatic injury and bleeding, one had left gastric artery injury and bleeding, but all patients can be effectively treated during the operation with no serious incidents. Martinez et $\mathrm{al}^{11}$ performed 


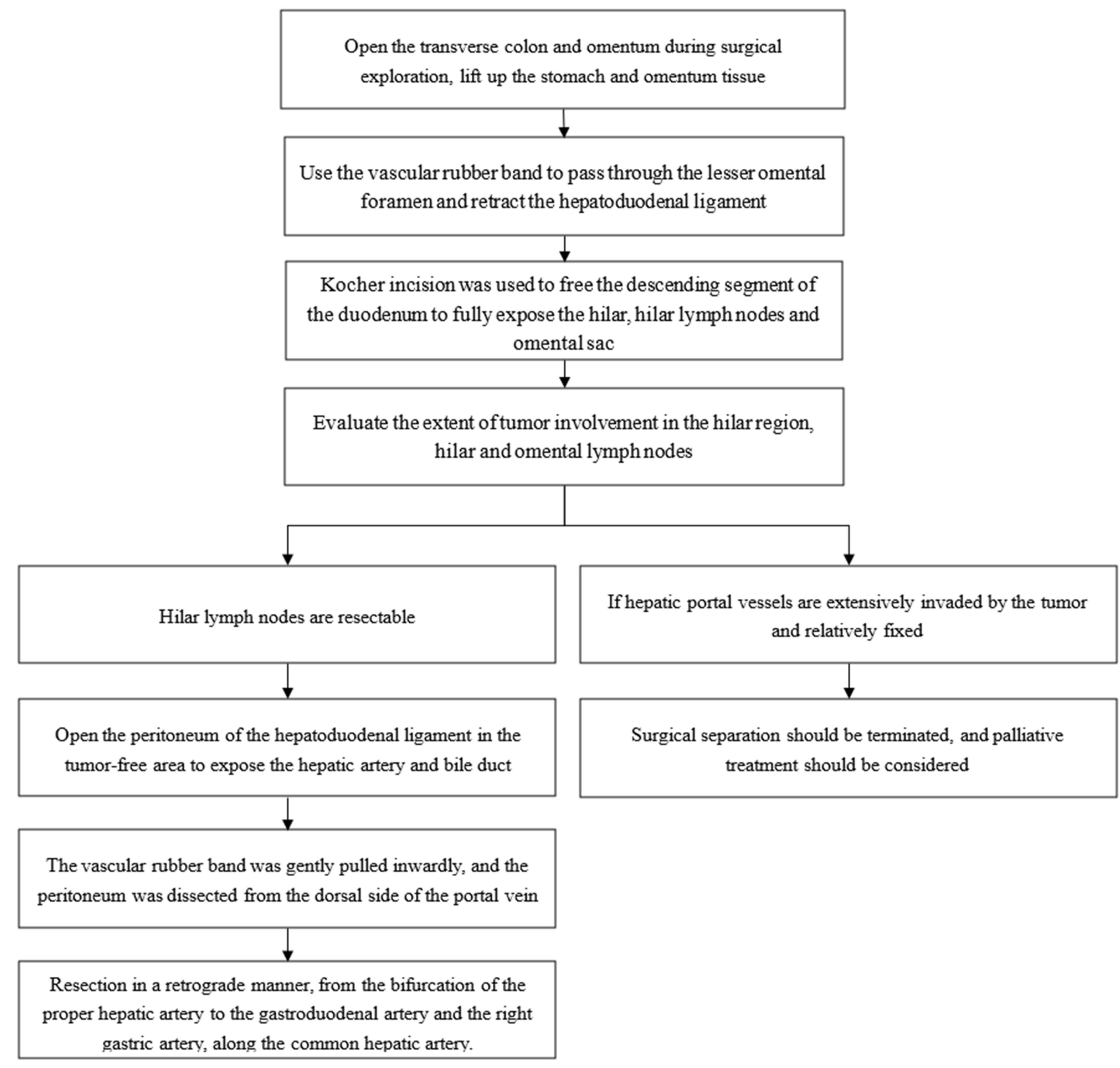

Figure 3 Surgical pipeline of hepatic hilar regional lymph node resection in cytoreductive surgery for advanced ovarian cancer.

hilar tumor resection on 28 patients with advanced ovaries. One case of bile duct injury occurred; they repaired and intraoperative drainage was inserted during the operation. The biliary duct drainage tube was removed 4 months after the operation without any remaining complications (Table 1). Therefore, when the surgical technical conditions are mature, it is safe and feasible to perform hilar lymph node resection, the complications are acceptable and controllable. ${ }^{12}$

\section{Conclusion}

Lymph node metastasis in the hepatic hilar area is a risk factor for poor prognosis of ovarian cancer. However, the anatomical structure of this area is complicated, which greatly increases the difficulty of surgical resection. In recent years, with the improvement of surgical skills of gynecological oncologists and the popularization of multidisciplinary collaboration, difficult upper abdominal surgery including the hepatic hilar area will gradually become the norm for 
Table I Summary of Research of Hepatic Hilar Region Lymph Node Resection in Cytoreductive Surgery for Advanced Ovarian Cancer

\begin{tabular}{|c|c|c|c|c|c|c|}
\hline & $\begin{array}{l}\text { Number } \\
\text { of } \\
\text { Patients }\end{array}$ & $\begin{array}{l}\text { Incidence of PH/ } \\
\text { HCL Disease }\end{array}$ & $\begin{array}{l}\text { Diagnosis } \\
\text { Method }\end{array}$ & $\begin{array}{l}\text { Surgery } \\
\text { Related } \\
\text { Morbidity }\end{array}$ & $\begin{array}{l}\text { Complications } \\
\text { Directly Related to } \\
\text { Resection of Disease } \\
\text { at the Porta Hepatis }\end{array}$ & DFS/OS \\
\hline Martinez et $a l^{5}$ & 28 & $\begin{array}{l}53.6 \% \text { (celiac nodes) } \\
67.9 \% \text { (porta hepatis) }\end{array}$ & $\begin{array}{l}\text { Intraoperative } \\
\text { palpation }\end{array}$ & $35.7 \%$ & $\begin{array}{l}\text { One lateral common bile } \\
\text { duct injury occurred } \\
\text { during resection of tumor } \\
\text { at the porta hepatis, and } \\
\text { primary suture with } \\
\text { drainage followed by } \\
\text { intraoperative } \\
\text { cholangiography to was } \\
\text { performed. }\end{array}$ & NA \\
\hline Song et $\mathrm{al}^{10}$ & 155 & $7.1 \%(11 / 155)$ & $\begin{array}{l}\text { Preoperative } \\
\text { physical } \\
\text { examination and } \\
\text { an } \\
\text { abdominopelvic } \\
\text { and chest CT }\end{array}$ & $36.4 \%$ & $\begin{array}{l}\text { Intraoperative } \\
\text { complications specific for } \\
\text { tumor resection at the } \\
\text { porta hepatis, such as } \\
\text { hemorrhage by injury to } \\
\text { the hepatic artery or } \\
\text { portal vein, bile leakage, } \\
\text { and liver damage were } \\
\text { not observed. }\end{array}$ & $\begin{array}{l}\text { Five of II patients had } \\
\text { recurrent disease at } \\
\text { median } 8 \text { months (range, } \\
\mathrm{I}-\mid 3 \text { ) after the surgery } \\
\text { with a median follow-up } \\
\text { of } 8 \text { months (range, 3-2I } \\
\text { months). }\end{array}$ \\
\hline $\begin{array}{l}\text { Raspagliesi } \\
\text { et } \mathrm{al}^{6}\end{array}$ & 37 & $67 \%(25 / 37)$ & $\begin{array}{l}\text { Total body CT } \\
\text { scan: with PET } \\
\text { scan performed } \\
\text { if clinically } \\
\text { indicated } \\
\text { +intraoperative } \\
\text { findings }\end{array}$ & $21.6 \%$ & $\begin{array}{l}2 / 25 \text { (I bleeding due to } \\
\text { liver damage and I due to } \\
\text { left gastric artery injury) }\end{array}$ & NA \\
\hline Tozzi et al $\mathbf{l}^{7}$ & 216 & $14.3 \%(3|/ 2| 6)$ & $\begin{array}{l}\text { CT scan and } \\
\text { exploratory } \\
\text { laparoscopy }\end{array}$ & $29.2 \%$ & None & 19 months $/ 42$ months \\
\hline
\end{tabular}

advanced ovarian cancer surgical treatment. ${ }^{23}$ Proper hilar lymph node resection can not only effectively reduce the tumor burden and achieve the goal of tumor bulk reduction, it is also expected to improve the survival and prognosis of patients. It has become possible for daily clinical practice. However, the current studies are mostly retrospective case analysis or small sample studies. The safety and feasibility of hilar regional lymph node resection and its clinical application value need to be explored and verified by more prospective, multicenter, large-sample clinical studies in the future.

\section{Disclosure}

The authors report no conflicts of interest in this work.

\section{References}

1. Cook SA, Tinker AV. PARP inhibitors and the evolving landscape of ovarian cancer management: a review. BioDrugs. 2019;33(3):255-273. doi:10.1007/s40259-019-00347-4

2. Moschetta M, Boussios S, Rassy E, Samartzis EP, Funingana G, Uccello M. Neoadjuvant treatment for newly diagnosed advanced ovarian cancer: where do we stand and where are we going? Ann Transl Med. 2020;8(24):1710. doi:10.21037/atm-20-1683

3. Boussios S, Moschetta M, Zarkavelis G, Papadaki A, Kefas A, Tatsi K. Ovarian sex-cord stromal tumours and small cell tumours: pathological, genetic and management aspects. Crit Rev Oncol Hematol. 2017;120:43-51. doi:10.1016/j.critrevonc.2017.10.007

4. Armstrong DK, Alvarez RD, Bakkum-Gamez JN, et al. Ovarian cancer, version 2.2020, NCCN clinical practice guidelines in oncology. J Natl Compr Canc Netw. 2021;19(2):191-226. doi:10.6004/ jncen.2021.0007 
5. Martinez A, Pomel C, Mery E, Querleu D, Gladieff L, Ferron G. Celiac lymph node resection and porta hepatis disease resection in advanced or recurrent epithelial ovarian, fallopian tube, and primary peritoneal cancer. Gynecol Oncol. 2011;121(2):258-263. doi:10.1016/j.ygyno.2010.12.328

6. Raspagliesi F, Ditto A, Martinelli F, Haeusler E, Lorusso D. Advanced ovarian cancer: omental bursa, lesser omentum, celiac, portal and triad nodes spread as cause of inaccurate evaluation of residual tumor. Gynecol Oncol. 2013;129(1):92-96. doi:10.1016/j. ygyno.2013.01.024

7. Tozzi R, Traill Z, Garruto Campanile R, et al. Porta hepatis peritonectomy and hepato-celiac lymphadenectomy in patients with stage IIIC-IV ovarian cancer: diagnostic pathway, surgical technique and outcomes. Gynecol Oncol. 2016;143(1):35-39. doi:10.1016/j.ygyno.2016.08.232

8. Ramesh Babu CS, Sharma M. Biliary tract anatomy and its relationship with venous drainage. J Clin Exp Hepatol. 2014;4(Suppl 1): S18-S26. doi:10.1016/j.jceh.2013.05.002

9. Li J, Zhou MH, Ma WJ, Li FY, Deng YL. Extended lymphadenectomy in hilar cholangiocarcinoma: what it will bring? World J Gastroenterol. 2020;26(24):3318-3325. doi:10.3748/wjg.v26.i24.3318

10. Song YJ, Lim MC, Kang S, et al. Extended cytoreduction of tumor at the porta hepatis by an interdisciplinary team approach in patients with epithelial ovarian cancer. Gynecol Oncol. 2011;121(2):253-257. doi:10.1016/j.ygyno.2010.12.350

11. Martínez A, Pomel C, Filleron T, et al. Prognostic relevance of celiac lymph node involvement in ovarian cancer. Int $J$ Gynecol Cancer. 2014;24(1):48-53. doi:10.1097/IGC.0000000000000041

12. Gallotta V, Ferrandina G, Vizzielli G, et al. Hepatoceliac lymph node involvement in advanced ovarian cancer patients: prognostic role and clinical considerations. Ann Surg Oncol. 2017;24(11):3413-3421. doi:10.1245/s10434-017-6005-1

13. Griffiths CT. Surgical resection of tumor bulk in the primary treatment of ovarian carcinoma. Natl Cancer Inst Monogr. 1975;42:101-104.

14. Bristow RE, Tomacruz RS, Armstrong DK, Trimble EL, Montz FJ. Survival effect of maximal cytoreductive surgery for advanced ovarian carcinoma during the platinum era: a meta-analysis. J Clin Oncol. 2002;20(5):1248-1259. doi:10.1200/JCO.2002.20.5.1248
15. Aletti GD, Dowdy SC, Podratz KC, Cliby WA. Surgical treatment of diaphragm disease correlates with improved survival in optimally debulked advanced stage ovarian cancer. Gynecol Oncol. 2006;100 (2):283-287. doi:10.1016/j.ygyno.2005.08.027

16. Fu X, Ma Q, Li J. The risk factors of retroperitoneal lymph node metastasis in ovarian cancer and the observation of MRI and CT imaging characteristics. Chin J CT MRI. 2020;18(9):134-138.

17. Yu Z, Meng C, Zhao C, Chen B, Zhao X, Li W. Assessment of ovarian cancer lymph node metastasis based on $\mathrm{CT}$ image texture analysis technique. Mod Oncol. 2020;28(18):3222-3226.

18. Kasper SM, Dueholm M, Marinovskij E, Blaakær J. Imaging diagnostics in ovarian cancer: magnetic resonance imaging and a scoring system guiding choice of primary treatment. Eur J Obstet Gynecol Reprod Biol. 2017;210:83-89. doi:10.1016/j.ejogrb.2016.10.034

19. Javadi S, Ganeshan DM, Qayyum A, Iyer RB, Bhosale P. Ovarian cancer, the revised FIGO staging system, and the role of imaging. AJR Am J Roentgenol. 2016;206(6):1351-1360. doi:10.2214/AJR.15.15199

20. Kemppainen J, Hynninen J, Virtanen J, Seppänen M. PET/CT for evaluation of ovarian cancer. Semin Nucl Med. 2019;49(6):484-492. doi:10.1053/j.semnuclmed.2019.06.010

21. Khiewvan B, Torigian DA, Emamzadehfard S, et al. An update on the role of PET/CT and PET/MRI in ovarian cancer. Eur J Nucl Med Mol Imaging. 2017;44(6):1079-1091. doi:10.1007/s00259-017-3638-Z

22. Tato-Varela S, Kuhn W. Impact of retroperitoneal lymph node dissection in ovarian cancer - time for paradigm shift? Horm Mol Biol Clin Investig. 2019;41(3). doi:10.1515/hmbci-2019-0020

23. Angeles MA, Ferron G, Cabarrou B, et al. Prognostic impact of celiac lymph node involvement in patients after frontline treatment for advanced ovarian cancer. Eur J Surg Oncol. 2019;45 (8):1410-1416. doi:10.1016/j.ejso.2019.02.018

\section{Publish your work in this journal}

Cancer Management and Research is an international, peer-reviewed open access journal focusing on cancer research and the optimal use of preventative and integrated treatment interventions to achieve improved outcomes, enhanced survival and quality of life for the cancer patient.
The manuscript management system is completely online and includes a very quick and fair peer-review system, which is all easy to use. Visit http://www.dovepress.com/testimonials.php to read real quotes from published authors. 